\title{
Achalasia - An Update
}

\author{
Joel E Richter, MD, FACP, MACG
}

Department of Medicine, Temple University School of Medicine, Philadelphia, USA

Achalasia is an esophageal motility disorder of unknown cause, characterized by aperistalsis of the esophageal body and impaired lower esophageal sphincter relaxation. Patients present at all ages, primarily with dysphagia for solids/liquids and bland regurgitation. The diagnosis is suggested by barium esophagram and confirmed by esophageal manometry. Achalasia cannot be cured. Instead, our goal is to relieve symptoms, improve esophageal emptying and prevent the development of megaesophagus. The most successful therapies are pneumatic dilation and surgical myotomy. The overall success rate of graded pneumatic dilation is $78 \%$, with women and older patients responding best. Laparoscopic myotomy, usually combined with a partial fundoplication, has an overall success rate of $87 \%$. Young patients, especially men, are the best candidates for surgical myotomy. Botulinum toxin injection into the lower esophageal sphincter and smooth muscle relaxants are usually reserved for older patients or those with co-morbid illness. The prognosis for achalasia patients to return to near normal swallowing is good, but the disease is rarely "cured" with a single procedure and intermittent touch-up procedures may be required.

(J Neurogastroenterol Motil 2010;16:232-242)

\section{Key Words}

Achalasia; Balloon dilation; Esophageal sphincter lower; Muscle, smooth; Botulinum toxin

\section{Introduction}

Achalasia is the most recognized motor disorder of the esophagus, and is the only primary motility disorder with an established pathophysiology. The term means "failure to relax," and describes the primary predominant feature of this disorder, a poorly relaxing lower esophageal sphincter (LES) seen in association with aperistalsis of the esophageal body. The first case of achalasia was reported more than 300 years ago by Thomas Willis; where the patient's cardiospasm responded to dilation with a whalebone. ${ }^{1}$

\section{Epidemiology and Pathophysiology}

Achalasia occurs with equal frequency in men and women. There is no racial predilection. Case studies show an age distribution between birth and the nineth decade, with the peak incidence between 30 and 60 years of age. In children, it can be part of the Triple A syndrome, characterized by achalasia, alacrima and adrenocorticotropic hormone resistant adrenal insufficiency. Achalasia is an uncommon disease, but occurs frequently enough to be encountered at least yearly by most gastroenterologists. Esophageal specialists, both gastroenterologists and surgeons, may see 10 or more cases a year. ${ }^{2}$ The disease prevalence is ap-

Received: April 29, 2010 Revised: May 25, 2010 Accepted: May 26, 2010

(c) This is an Open Access article distributed under the terms of the Creative Commons Attribution Non-Commercial License (http://creativecommons. org/licenses/by-nc/3.0) which permits unrestricted non-commercial use, distribution, and reproduction in any medium, provided the original work is properly cited.

*Correspondence: Joel E Richter, MD, FACP, MACG

Department of Medicine, Temple University School of Medicine, 3401 North Broad Street, 801 Parkinson Pavilion, Philadelphia, PA 191940, USA

Financial support: None.

Tel: +1-215-707-5069, Fax: +1-215-707-9004, E-mail: jrichter@temple.edu

Conflicts of interest: None. 
proximately 10 cases per 100,000 population. Its incidence has been fairly stable over the last 50 years at approximately 0.5 cases per 100,000 population per year. The overall life expectancy of patients with achalasia does not differ from those of the general population. $^{3}$

The histologic abnormalities in patients with achalasia have been well described at autopsy or from myotomy specimens. ${ }^{4,5}$ The primary region of damage is the esophageal myenteric (Auerbach's) plexus, and includes prominent but patchy inflammatory response, consisting of predominantly $\mathrm{CD} 3$ and CD8 positive cytotoxic $T$ lymphocytes, variable numbers of eosinophils and mast cells, loss of ganglion cells and some degree of myenteric neurofibrosis. Early disease has more of an inflammatory component, with some of the ganglion cells appearing to be intact, while end stage disease is associated with complete loss of ganglion cells and replacement with myenteric fibrosis. ${ }^{5}$ Even during the early inflammatory stages of achalasia, there is a selective loss of postganglionic inhibitory neurons containing nitric oxide (NO) and vasoactive intestinal polypeptide. Since postganglionic excitatory neurons are spared, cholinergic stimulation continues unopposed, leading sometimes to high resting LES pressure. The loss of inhibitory input results in abnormal and usually incomplete LES relaxation. This occurs for all stimuli, including electrical field stimulation of muscle strips from achalasia patients, intravenous cholecystokinin, esophageal distension, and gastric distension fail to induce transient LES relaxation in achalasia patients. ${ }^{6}$ Aperistalsis is caused by the loss of the latency gradient that permits sequential contractions along the esophageal body, a process mediated by NO.

Although achalasia is the best characterized of the esophageal motility disorders, its pathogenesis is still not fully elucidated. Available data suggests that hereditary, degenerative, autoimmune and infectious factors are possible causes - the latter 2 being the most commonly accepted. ${ }^{7}$ The presence of cytotoxic $\mathrm{T}$ lymphocytes, IgM antibodies and evidence of complement activation and antibodies against myenteric neurons, especially in patients with specific HLA genotype (DQA1 × 0103 and DQB1 $\times 0603$ alleles), point toward an autoimmune origin of the myenteric ganglionitis. ${ }^{8}$ However, some of these antineuronal antibodies may be seen in healthy patients and patients with GERD, suggesting they may represent an epiphenomenon, and not a causative factor. ${ }^{9}$ Although these findings are all very interesting, it still remains obscure why only neurons in the esophagus and LES are destroyed. Furthermore, the exact stimulus initiating this immune response or the antigen targeted remains uni- dentified. The fact that achalasia is confined to the esophagus and LES has led to hypotheses that neurotropic viruses, especially viruses with predilection for squamous epithelium, may be involved. However, studies focusing on the presence of viral antibodies in the serum or viral DNA in esophageal tissue show conflicting results. ${ }^{10,11}$ On the other hand, a recent study suggests a causal role for a subpopulation of cytotoxic lymphocytes activated by the herpes simplex virus antigens or antigens on neurons similar to herpes simplex virus. ${ }^{12}$

\section{Clinical Presentation}

The diagnosis of achalasia should be suspected in any patients complaining of dysphagia for solids and liquids with regurgitation of bland food and saliva. The onset of the dysphagia is usually gradual, being described initially as an infrequent "fullness in the chest" or "sticking sensation," but usually occurs daily or with every meal by the time the patient sees a physician. Initially, the dysphagia may be primarily for solids; however, by the time of clinical presentation, nearly all complain of dysphagia for solids and liquids while eating and drinking, especially cold beverages. Various maneuvers, including "power swallows" and carbonated beverages, both of which increase intraesophageal pressure, may be used to improve esophageal emptying. Regurgitation becomes a problem with progression of the disease, especially when the esophagus becomes dilated. Regurgitation of bland, undigested retained foods or accumulated saliva, sometimes misdiagnosed as postnasal phlegm or bronchitis, occur postprandially and at night, often waking the patient from sleep because of coughing and choking. Rarely, aspiration pneumonia is a problem. Chest pain occurs in some patients, primarily at night, and is especially seen in patients with milder disease when the esophagus is minimally dilated. The mechanism of chest pain is unknown, but it is not simply repetitive episodes of simultaneous contractions, causing the esophageal lumen to be occluded. Whereas pneumatic dilation or surgery usually relieves dysphagia and regurgitation, the chest pain in achalasia patients responds much less predictably. Fortunately, the chest pain seems to get better over time, possibly as the esophagus dilates. ${ }^{13}$ Heartburn is a frequent complaint in achalasia, despite the fact that achalasia is not associated with increased episodes of acid reflux by $\mathrm{pH}$ monitoring. The cause of this symptom is speculative, but probably related to retention of acid beverages such as carbonated or fruit drinks and, in some cases, the production of lactic acid from retained food in a markedly dilated esophagus. Most achalasia 
patients have some degree of weight loss at presentation; however, the loss is usually only 5 to $20 \mathrm{lb}$ over months to years.

\section{Diagnostic Evaluation}

When achalasia is suspected, a barium esophagram with fluoroscopy is the best initial diagnostic test. The esophagus is usually dilated and sometimes tortuous, does not empty, and retained food and saliva produces an air-fluid level at the top of the barium column. The distal esophagus is characterized by a smooth tapering from the closed LES, resembling a bird's beak, and sometimes an epiphrenic diverticulum is noted. Fluoroscopy always shows a lack of peristalsis, replaced by to-and-fro movement in the supine position. We have popularized a modification of the barium esophagram known as the timed barium swallow. ${ }^{14}$ The test is individualized for each patient and primarily assesses esophageal emptying of barium in the upright position over 5 minutes. Tests can be repeated serially after therapy to evaluate esophageal emptying and correlate it with the patients' symptoms.

Esophageal manometry is required to establish the diagnosis of achalasia and must be done in any patient where invasive treatments such as pneumatic dilation or surgical myotomy are planned. Because achalasia only involves the smooth muscles of the esophagus, the manometry abnormalities are confined to the

\section{A}

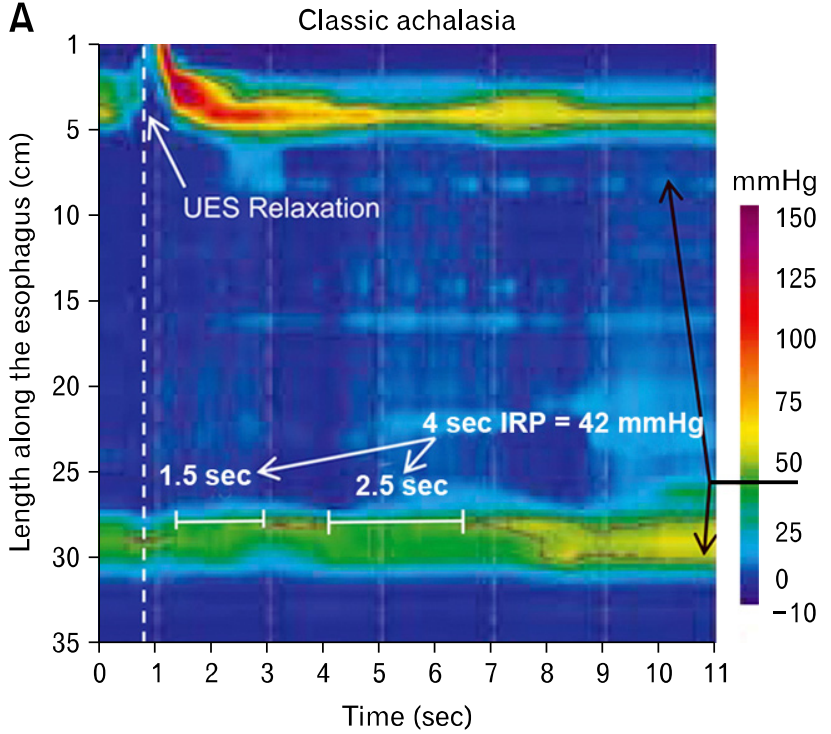

C

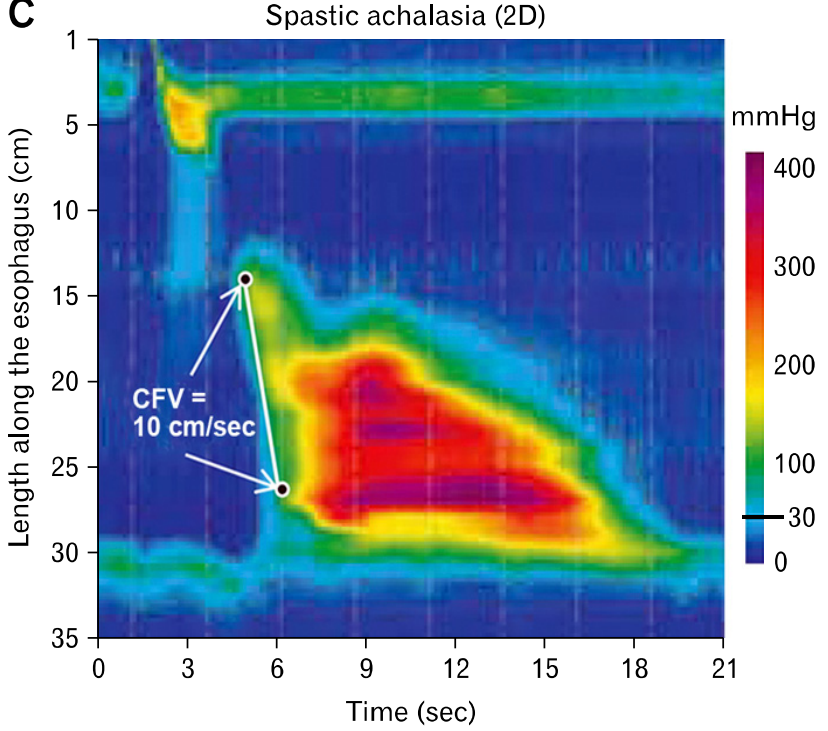

B

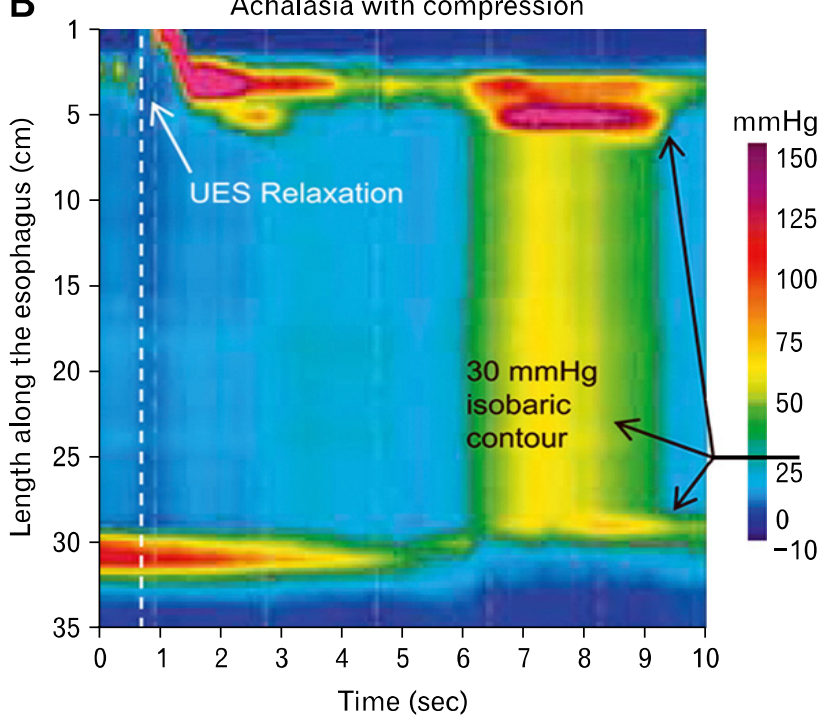

Figure 1. Achalasia subtypes by high resolution manometry. (A) Type I (classic achalasia) - there is no significant pressurization within the esophageal body (all dark blue) and impaired lower esophageal sphincter (LES) relaxation (IRP $=42 \mathrm{mmHg}$ ). (B) Type II (achalasia with compression) - water swallows cause rapid pan-esophageal pressurization which may exceed LES pressure, causing the esophagus to empty. (C) Type III (spastic achalasia) - although this is also associated with rapidly propagated pressurization, the pressurization is attributable to an abnormal lumen obliterating contraction. (Modified from: Pandolfino JE, Fox MR, Bredenoord AJ, Kahrilas PJ. High resolution manometry in clinical practice: utilizing pressure topography to classify oeosophageal motility abnormalities. Neurogastroenterol Motil 2009;21:796-806). UES, upper esophageal sphincter; IRP, integrated relaxation pressure; CFV, contractile front velocity. 
distal two-thirds of the esophagus. All patients have at least 2 pathognomonic abnormalities: aperistalsis and abnormal LES relaxation. The aperistalsis is usually characterized by low amplitude, simultaneous mirror image (isobaric) waves, due to a common cavity phenomenon. Physiologically, the low amplitude waves (usually $<30 \mathrm{mmHg}$ ) represent simultaneous fluid movement in a fluid filled dilated esophagus, rather than true lumen occluding contractions. When pressure waves have a higher amplitude and different morphology, indicating active contractions of the esophageal body, it is called "vigorous" achalasia. Abnormal LES relaxation is seen in all achalasia patients; about 70\%-80\% have absent or incomplete LES relaxation with wet swallows, while the remainder will have complete but shortened LES relaxation ( $<6$ seconds). LES resting pressure may be elevated in approximately $50 \%$ of patients with achalasia. Sometimes, an increase in the esophageal baseline greater than gastric baseline is seen due to retention of food and saliva.

The recent introduction of high resolution manometry has greatly helped in making the diagnosis of achalasia. ${ }^{15,16}$ It allows a more careful evaluation of LES and esophagogastric junction relaxation using the integrated relaxation pressure. As reported by the Northwestern group in a series of achalasia patients, ${ }^{15}$ the traditional LES nadir pressure had a false negative rate of $48 \%$, while an integrated relaxation pressure $<15 \mathrm{mmHg}$ was seen in all but $3 \%$ of achalasia patients. The group also described 3 patterns of achalasia: Type I - impaired relaxation with esophageal dilation and negligible esophageal pressurization; Type II pan-esophageal pressurization and Type III - spastic contractions of the distal esophageal segment (Fig. 1). ${ }^{16}$

Pseudoachalasia is a clinical syndrome similar to achalasia, being seen in approximately $2 \%-4 \%$ of patients suspected with achalasia. ${ }^{17}$ In general, patients with pseudoachalasia are older and have a shorter history of dysphagia and marked weight loss. However, this triad tends to have poor specificity. ${ }^{18}$ The most common cause of pseudoachalasia is a malignancy infiltrating the gastroesophageal junction. Therefore, all patients with suspected achalasia need a careful upper endoscopy with close examination of the cardia and gastroesophageal junction. If pseudoachalasia is still suspected, endoscopic ultrasound with a small $20 \mathrm{mHz}$ probe or computed tomography scanning of the chest may be helpful.

Although the symptoms of achalasia are relatively classic, and the diagnostic tests, especially barium X-rays and manometry, readily available, there is still a considerable delay between the onset of symptoms and the diagnosis. In one report, patients on average reported symptoms of dysphagia for approximately 5 years and had seen several physicians before the correct diagnosis was made. Interestingly, the frequent delay in the diagnosis was not due to an atypical clinical presentation of the disease, but rather to misinterpretation of typical findings by the physician consulted. ${ }^{19}$

\section{Treatment of Achalasia}

No treatment can restore muscular activity to the denervated esophagus in achalasia. Esophageal aperistalsis and impaired LES relaxation are rarely, if ever, reversed by any mode of therapy. Therefore, every treatment for achalasia is directed to reducing the pressure gradient across the LES with 3 goals of: (1) relieving patients' symptoms, especially dysphagia and bland regurgitation, (2) improving esophageal emptying by disrupting the poorly relaxing LES and (3) preventing the development of megaesophagus.

The disruption of the LES gradient is best accomplished by pneumatic dilation or surgical myotomy and, less effectively, by pharmacologic agents. The symptoms of regurgitation and dysphagia are the easiest to treat, but chest pain can be problematic in some patients. ${ }^{13}$ Overall, using single or multiple modalities of treatment, over $90 \%$ of achalasia patients will do well. ${ }^{20}$ However, achalasia is never "cured" and touch-up therapies after pneumatic dilation or Heller myotomies are often needed. Therefore, I recommend that all achalasia patients be followed up every 1 to 2 years by a gastroenterologist or surgeon familiar with the disease. In my experience, the timed barium swallow is very helpful in following these patients, ${ }^{21}$ however, my colleagues in Europe prefer to do serial measurements of LES pressure. ${ }^{22,23}$

\section{Pneumatic Dilation}

Pneumatic dilation aims at disrupting the LES by forceful dilation using air filled balloons. This procedure has become easier and more standardized with the development of the Rigiflex balloon system (Boston Scientific Corporation, MA, USA). These are noncompliant polyethylene balloons available in 3 diameters $(3.0,3.5$ and $4.0 \mathrm{~cm})$, on a flexible catheter that can be placed over a guidewire at endoscopy. The catheter within the balloon has radiopaque markers which can help identify its location at fluoroscopy. Briefly, the procedure is done at the time of endoscopy, with the balloon placed over the guidewire and positioned across the LES. This position is confirmed either by fluoroscopy or endoscopy. The balloon is then gradually inflated until 
the waist, caused by the spastic LES, is flattened or effaced. The pressure required is usually 7-12 psi of air, held for 15-60 seconds. Sometimes multiple balloon distensions are done at the same setting. Some investigators only perform one dilation, ${ }^{22}$ but most use a graded dilation protocol starting with $3.0 \mathrm{~cm}$, followed by $3.5 \mathrm{~cm}$ and then $4.0 \mathrm{~cm}$ balloon dilation, in subsequent sessions. ${ }^{24} \mathrm{~A}$ few European centers perform serial progressive dilations over several days, until the manometrically measured LES pressure is below $10-15 \mathrm{mmHg}{ }^{22,23}$ Pneumatic dilation is now routinely done in outpatient centers, with the patient being observed for up to 6 hours, to ensure that no complications have occurred. Some perform Gastrografin followed by barium swallows to exclude perforations; others do not recommend obtaining routine barium X-ray films unless clinically indicated.

Table 1 summarizes the good to excellent symptom relief with the Rigiflex balloons in 1,144 patients. ${ }^{25}$ These 24 studies, with an average follow-up of 37 months, found that the clinical response improves in a graded fashion with increasing size of the balloon diameter - good to excellent response in $74 \%, 86 \%$ and $90 \%$ with the 3.0, 3.5 and 4.0 balloons, respectively. Over a third of achalasia patients treated with pneumatic dilation will experience symptom recurrence during a 4 to 6-year period of follow-up. Long-term remission can be achieved in virtually all of these patients treated by repeated pneumatic dilation according to an "on demand" strategy, based on symptom recurrence. ${ }^{26}$ Therefore, in clinical practice, pneumatic dilation is a non-surgical treatment that will require periodic "touch ups" over the life of the patient. Pneumatic dilation is the most cost effective method for treating achalasia, when compared to Heller myotomy or Botox, over a time period of 5 to 10 years. ${ }^{27,28}$

With the standardization of the Rigiflex balloons, we are beginning to define the risk factors for relapse after pneumatic dila-

Table 1. Long-term Efficacy and Complications of Rigiflex Balloon Dilation Versus Heller Myotomy for Achalasia

\begin{tabular}{lcc}
\hline & $\begin{array}{c}\text { Rigiflex } \\
\text { balloon }\end{array}$ & $\begin{array}{c}\text { Laparoscopic } \\
\text { myotomy }\end{array}$ \\
\hline Number of studies & 24 & 30 \\
Number of patients & 1,144 & 1,487 \\
$\begin{array}{l}\text { Excellent/good symptom } \\
\text { response (\%) }\end{array}$ & 78.0 & 86.7 \\
Follow up (months) & 37 & 32 \\
Complications (\%) & 1.9 & 18.0 \\
& (perforation) & $\begin{array}{l}\text { (gastroesophageal } \\
\text { reflux) }\end{array}$ \\
& &
\end{tabular}

${ }^{\mathrm{a}}$ Surgical series with over 10 patients. tion (Table 2$)$. These are mainly young age ( $<40$ years), male gender, single dilation with a $3.0 \mathrm{~cm}$ balloon, posttreatment LES pressure $>10-15 \mathrm{mmHg}$, and poor esophageal emptying on timed barium swallow. The effects of age on the success of pneumatic dilation are most reproducible from as far back as 1971, even with the older balloons. ${ }^{29}$ For example, Eckardt et al, ${ }^{30}$ using a $4 \mathrm{~cm}$ Brown-McHardy dilator, demonstrated a 5-year remission rate of $16 \%$ for patients younger than 40 years, compared to $58 \%$ for those older than 40 years. Recent studies suggest young men do not do as well as young women with the pneumatic dilation. In a study of 126 patients, Ghoshal et $\mathrm{al}^{31}$ found that male gender, but not age, was independently associated with poor outcome after dilation. Another large study from the Cleveland Clinic (106 patients, 51 women) confirmed the importance of age but also found gender to be equally important. ${ }^{32}$ Men, up to age 50 years, did not do well with a single $3.0 \mathrm{~cm}$ Rigiflex pneumatic dilation. However, only young women ( $<35$ years of age) did poorly with pneumatic dilation, while most older women had sustained relief over at least 5 years with a single pneumatic dilation.

Physiologic studies can also predict the long-term success rate of pneumatic dilation. Eckhardt and colleagues ${ }^{22}$ reported that all patients with post procedure LES pressure $<10 \mathrm{mmHg}$ were in remission after 2 years, compared with $71 \%$ for pressures between 10-20 $\mathrm{mmHg}$ and $23 \%$ for pressures over $20 \mathrm{mmHg}$. More recently, the Leuven group observed that $66 \%$ of their patients with post procedure LES pressure $<15 \mathrm{mmHg}$ were in symptomatic remission after an average of 6 years. ${ }^{23}$ Using the timed barium swallow, we found that patients with complete symptom relief, correlating with marked improvement of esophageal emptying, were more likely to do well at 3 years than those with symptom relief, but poor esophageal emptying ( $82 \%$ vs $10 \%$, respectively). ${ }^{21} \mathrm{~A}$ randomized clinical trial of pneumatic dilation versus surgery found that patients with $<50 \%$ improve-

Table 2. Pneumatic Dilation: Predictors of Relapse

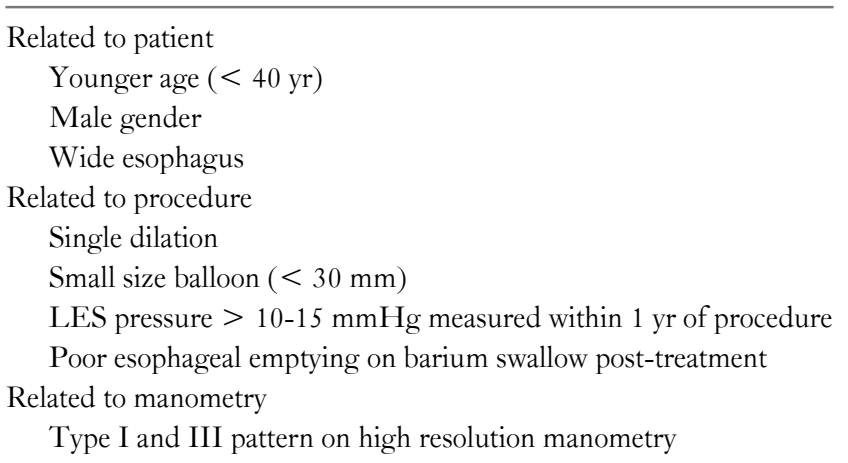


ment in the height of the barium column at 1 minute post treatment had a $40 \%$ risk of treatment failure during follow up. ${ }^{33}$ Most recently, the Northwestern group observed that patients with Type II achalasia pattern (esophageal pressurization) on high resolution manometry were more likely to respond to any therapy (Botox 71\%, pneumatic dilation $91 \%$ and Heller myotomy $100 \%$ ), compared to Type I (56\% overall) and Type III (29\% overall). ${ }^{16}$ This was a single center study whose authors are enthusiastic about high resolution manometry, therefore, confirmation by other centers of excellence are needed.

The only absolute contraindication to pneumatic dilation is poor cardiopulmonary status or other comorbid illnesses preventing surgery, should an esophageal perforation occur. Some have suggested that patients with vigorous achalasia, achalasia associated with epiphrenic diverticulum or hiatal hernia, malnutrition, or more than 1 previous dilation may have an increased risk of perforation. However, a retrospective study of 237 patients found no difference in clinical, endoscopic, manometric or radiographic characteristics among 7 who had perforations, compared to the 230 who did not. ${ }^{34}$ Pneumatic dilation can be safely done after a failed Heller myotomy, although larger diameter balloons are required (I usually start with a $3.5 \mathrm{~cm}$ balloon) and the success rate is not as good. ${ }^{35}$

The most serious complication from pneumatic dilation is esophageal perforation, with an overall rate in experienced hands of $1.9 \%$ (range $0 \%-16 \%$ ). ${ }^{25}$ Treatment may be conservative with antibiotics and total parenteral nutrition, or surgical repair through a thoracotomy may be required. Other minor complications include chest pain (15\% of patients), aspiration pneumonia, hematemesis, fever, esophageal mucosal tear and hematoma. Severe complications of gastroesophageal reflux disease (esophagitis, peptic stricture and Barrett's esophagus) are rare after pneumatic dilation, but $15 \%-35 \%$ of patients have heartburn, responding to proton pump inhibitors. ${ }^{25}$

\section{Laparoscopic Heller Myotomy}

The first successful surgery for achalasia was performed in 1913, by the German surgeon Ernest Heller. ${ }^{36}$ This surgery consisted of an anterior and posterior (double) lower esophageal myotomy through a laparotomy. Subsequently, the operation was modified to a single anterior myotomy performed usually through a left posterior thoracotomy. This operation was the primary surgical treatment for achalasia, until the mid 1990's, with reported good success rate (60\%-94\%) but high postoperative morbidity, making this treatment much less attractive. ${ }^{37}$ This dramatically changed with the introduction of the minimally invasive myotomy by Pellegrini and coworkers, ${ }^{38}$ in 1992 . Initially performed through the chest, the overall success of the laparoscopic operation through the abdomen is superior to the thorascopic approach. Patients are usually hospitalized for less than 48 hours and can return to work within 1 to 2 weeks. Recent improvements on the operation have included extending the myotomy $2-3 \mathrm{~cm}$ onto the proximal stomach to cut the gastric sling fibers, further decreasing LES pressure and improving dysphagia. ${ }^{39}$ This more aggressive myotomy accentuates the risk for postoperative gastroesophageal reflux; therefore, the consensus is to add an incomplete fundoplication, either an anterior Dor or posterior Toupet, to prevent this complication. ${ }^{40}$

Table 1 summarizes the good to excellent relief with laparoscopic Heller myotomy in nearly 1,500 patients. ${ }^{25}$ Younger patients, especially men and patients with higher LES pressures, may benefit most from primary surgery. Importantly, patients who fail pneumatic dilation or Botox treatment can be successfully treated with surgical myotomy. ${ }^{32,41}$ However, repeated Botox injections significantly hinder the dissection of the submucosal plane, leading to mucosal perforations in $7 \%-15 \%$ of operations. ${ }^{25}$ Although these perforations are usually recognized and repaired at the time of the initial operation, some studies suggest a negative effect on long term results. For example, Portale et $\mathrm{al}^{41}$ found the myotomy success rate of 19 patients previously treated with pneumatic dilation was $94 \%$ at 5 years, but only $75 \%$ for the 26 patients previously treated with Botox. Recurrence of dysphagia after a laparoscopic Heller myotomy is usually the result of an incomplete myotomy, particularly on the gastric side, esophageal scarring, obstruction by the fundoplication, megaesophagus or complications of severe GERD, including esophagitis or peptic stricture. Surgical expertise is key, with most complications occurring in the first 50 operations. ${ }^{42}$ Surgery is the most costly treatment for achalasia. ${ }^{27}$ However, it may be cost-effective, but only if its effectiveness reliably lasts at least 10 years. ${ }^{28}$

Although the short term results of laparoscopic Heller myotomy are excellent, it remains to be seen if the long term results are as favorable. Three groups have recently reported the long term results of laparoscopic Heller myotomy (mean follow up between 5.3 and 11.2 years) in 179 patients. ${ }^{43-45}$ Deterioration over time seems to occur with some striking consistency in these multinational studies; $18 \%$ required pneumatic dilation, $5 \%$ Botox injection and 5\%-10\% required repeat myotomy or esophagectomy.

Surgical complications of laparoscopic Heller myotomy in- 
clude death (0.1\%) and esophageal perforation $(7 \%-15 \%) .{ }^{25}$ The most common long term problem is chronic GERD and its sequelae, occurring overall in $18 \%$ of patients (range 5\%-55\%). ${ }^{25}$ Most of these patients have reflux symptoms; some esophagitis, and rarely Barrett's esophagus and secondary adenocarcinoma of the esophagus have been reported after Heller myotomy. The addition of an incomplete fundoplication decreases, but does not eliminate, the complications of GERD. ${ }^{40}$ A recent study by Csendes et al, ${ }^{46}$ illustrates the potential for GERD complications, especially among patients followed for over 10 years. This study reported on 67 patients with Heller myotomy and Dor fundoplication after open laparotomy with a mean follow up of nearly 16 years (range 6.6\%-30 years). Overall, $31 \%$ of the patients developed GERD, and $55 \%$ had abnormal $\mathrm{pH}$ studies 20 years after their myotomy. Importantly, 9 patients (13\%) developed Barrett's esophagus (6 short segment and 3 long segment), with the frequency increasing over time, reaching $30 \%$ after 20 years. In this series, poor or failed results were seen in $22.4 \%$ of the patients, but only 1 was due to an incomplete myotomy, with the remaining 14 due to complications of severe GERD. These alarming results may not be translatable to the laparoscopic operation, where the minor dissection of the perihiatal tissue theoretically should reduce the risk of postoperative GERD. However, careful studies will be required to address this concern.

\section{Pneumatic Dilation or Surgical Myotomy?}

Ideally, the choice between 2 treatment options should be based upon prospective, randomized comparative studies. Studies comparing pneumatic dilation with the Rigiflex balloon and laparoscopic Heller myotomy have recently been reported. These studies are appearing at a critical time, when many gastroenterologists have stopped performing pneumatic dilations and the laparoscopic technique has made Heller myotomy the most favored treatment for achalasia.

A large study from the Cleveland Clinic compared 106 patients treated with Rigiflex balloons by a single gastroenterologist, and 73 undergoing primarily laparoscopic Heller myotomy (20 had failed pneumatic dilation and crossed over to surgery) by a single esophageal surgeon. ${ }^{32}$ The success of graded pneumatic dilation and myotomy, defined as dysphagia/regurgitation $<3$ times a week or freedom from alternative treatment, was similar; $96 \%$ versus $89 \%$ at 6 months, decreasing to $44 \%$ versus $57 \%$ at 6 years. Causes of symptom recurrence were in- completely treated achalasia (96\% after pneumatic dilation vs $64 \%$ after myotomy) and complications of GERD ( $4 \%$ after dilation vs $36 \%$ after surgery).

To date, 2 small randomized studies have been reported comparing Rigiflex balloon dilation and laparoscopic myotomy. The first (16 pneumatic dilation, 14 Heller myotomy) found no difference in success rates. ${ }^{47}$ The second series (26 dilations, 25 surgery) with follow up for at least 12 months, observed 6 failures in the dilation group and 1 with surgery. This difference reached statistical significance $(p=0.04)$ in the per protocol analysis, but not the intention-to-treat analysis $(\mathrm{p}=0.09) .{ }^{48}$ Most recently, an achalasia trial involving 5 European countries randomized 94 patients to Rigiflex pneumatic dilation $(3.0$ and $3.5 \mathrm{~cm}$ ) and 106 to laparoscopic Heller myotomy with Dor fundoplication. ${ }^{49}$ After 2 years of follow up, both treatments had comparable success rates 92\% for pneumatic dilation and $87 \%$ for laparoscopic myotomy. Barium swallow emptying and LES pressures were similar for both groups. Four perforations occurred after pneumatic dilations, compared to 11 perioperatively recognized perforations (1 converted to open operation) during laparoscopic Heller myotomy.

Another method to address this issue is to investigate large population based databases comparing outcomes of these 2 procedures in typical practice settings. This was recently reported by Lopushinsky and $\mathrm{Urbach}^{50}$ in a retrospective longitudinal study in Ontario, Canada, from July 1991 to December 2002. A total of 1,461 persons aged 18 years or older received treatment for achalasia; $1,181(80.8 \%)$ had pneumatic dilation and 280 (19.2\%) had surgical myotomy as their first procedure. The cumulative risk of any subsequent intervention for achalasia (pneumatic dilation, myotomy or esophagectomy) after 1,5 and 10 years respectively was $36.8 \%, 56.2 \%$ and $63.5 \%$ after initial pneumatic dilation treatment, as compared to $16.4 \%, 30.3 \%$ and $37.5 \%$ after initial myotomy (hazard risk, 2.37; CI, 1.86-3.02; $\mathrm{p}<0.001$ ). The difference in risk between these 2 procedures was observed only when repeat pneumatic dilation was recorded as an adverse outcome. Since "on demand" pneumatic dilation is the accepted approach to treating achalasia, this cannot logically be viewed as failure of this treatment modality. Interestingly, the $33 \%$ need for subsequent pneumatic dilation and $18 \%$ risk of repeat surgery following myotomy were much higher than the current surgery literature suggests, probably defining the more realistic surgical experience in the clinical community. 


\section{Pharmacologic Treatments}

\section{Smooth muscle relaxants}

LES pressure can be transiently reduced by smooth muscle relaxants. ${ }^{51}$ Nitrates increase the NO concentration in smooth muscle cells, which subsequently increases cyclic guanosine monophosphate levels and results in muscle relaxation. Calcium is necessary for esophageal muscle contractions and its action is blocked by calcium antagonists. Nitrates and calcium channel blockers decrease LES pressure in a dose-dependent manner, with a maximum effect of approximately $50 \%$, thereby temporarily relieving dysphagia. These drugs are taken 15-30 minutes before meals, the improvement in dysphagia is usually incomplete and short lived, efficacy decreases with time, and side effects (headache, dizziness and pedal edema) are common. As a result, there is infrequently a place for these drugs in the clinical management of achalasia. The same holds true for sildenafil, a phosphodiesterase inhibitor that reduces the breakdown of cyclic guanosine monophosphate, the second messenger mediating NO induced relaxation. ${ }^{52}$

\section{Botulinum toxin}

Botulinum toxin (Botox) is a potent inhibitor of acetylcholine release from nerve endings. ${ }^{51}$ The inactive form is synthesized by the Clostridium botulinum bacteria. Botox cleaves SNAP-25, a cytoplasmic protein involved in the fusion of acetylcholine containing presymptomatic vesicles with the neuronal plasma mem- brane. Exocytosis of acetylcholine is inhibited and paralysis of the innervated muscle occurs. Botox counteracts the unopposed stimulation of the LES by cholinergic neurons, helping to restore the LES to a lower resting pressure. On average, Botox injections decrease LES pressure by $50 \%$, while partially improving esophageal emptying. ${ }^{51}$

Botox is commercially available in a lyophilized powder which should be stored below $-5^{\circ} \mathrm{C}$. The toxin is gently diluted with $5 \mathrm{~mL}$ of preservative-free sterile saline. Bubbles should not be formed during the mixing process, so as not to decrease the toxin's potency. Total dose of 100 units is endoscopically injected through a sclerotherapy needle into the LES in divided 25 unit aliquots, one in each quadrant of the sphincter. Increasing the dose to 200 units does not improve the success rate, but repeated 100 units may improve efficacy. One study reported that patients receiving 100 units of Botox, followed by a second injection of 100 units 30 days later, had an $80 \%$ remission rate at 12 months, compared with the $55 \%$ rate with the traditional regimen. ${ }^{53}$ The drug is contraindicated in patients with allergy to egg proteins. It should be administered cautiously to patients receiving aminoglycosides, because these medications may potentiate the effect of the toxin. The most common side effects of Botox injection is chest pain in $16 \%-25 \%$ of patients.

Based on numerous studies, some placebo-controlled, Botox markedly improves symptoms in approximately $75 \%$ of achalasia patients. ${ }^{25}$ However, symptoms recur in more than $50 \%$ of patients within 6 months, possibly because of regeneration of the affected receptors. ${ }^{53-55}$ Of course, those responding to the first injection of 100 units of Botox, nearly $75 \%$ will respond to a second

\section{Patient With Achalasia}

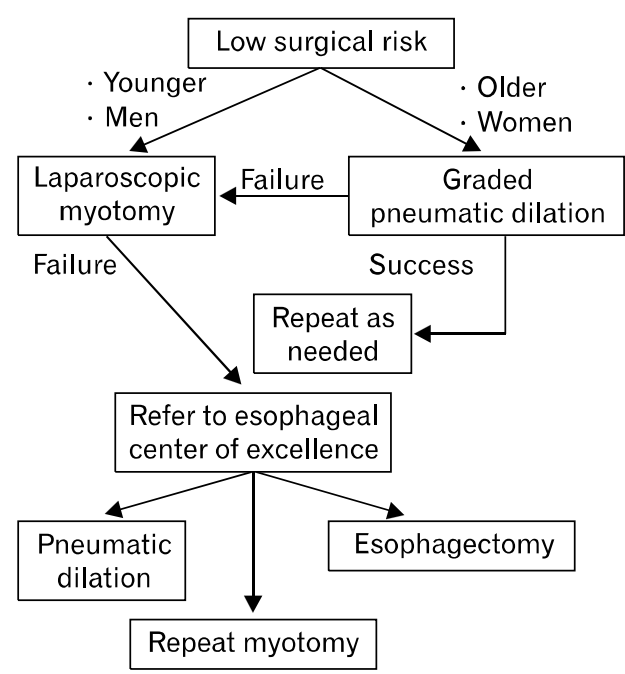

Figure 2. Suggested algorithm for the treatment of achalasia. Healthy patients with low risk of complications after surgery can be offered potentially definitive therapy with either pneumatic dilation or laparoscopic myotomy. Failures are best referred to Esophageal Centers of Excellence with expertise in pneumatic dilation, repeat myotomy, and esophagectomy. High risk patients, especially the elderly, are best treated with botulinum toxin injections. (Updated from the American College of Gastroenterology Practice Guidelines: Diagnosis and management of achalasia. American College of Gastroenterology Practice Parameter Committee. 1999;94:3406-3412, with permission). 
injection, but the response decreases with further injections, probably from antibody production to the foreign proteins. Less than $20 \%$ of the patients failing to respond to the initial Botox injection respond to a second injection. ${ }^{56}$ Patients older than 60 years of age, and those with vigorous achalasia, are more likely to get a sustained response, up to 1.5 to 2 years to Botox injection. ${ }^{54}$ Serial injections of Botox are required to give sustained relief, and comparison studies demonstrate its long term efficacy is inferior to pneumatic dilation or myotomy. ${ }^{55,57}$ A single vial of Botox costs approximately $\$ 500$. Serial Botox injections are more expensive than pneumatic dilation, because of the need for repeated injections. This treatment may have a cost advantage for patients living $<2$ years. $^{58}$

\section{General Recommendations}

For the newly diagnosed patient with achalasia, a suggested treatment algorithm ${ }^{59}$ is shown in Figure 2. Symptomatic healthy patients with achalasia should be given the option of graded pneumatic dilation or laparoscopic Heller myotomy since a review of the literature suggests relatively similar efficacy in the hands of experienced gastroenterologists and surgeons. ${ }^{25}$ Pneumatic dilation has the advantage of being an outpatient procedure, the pain is minimal, GERD is an infrequent problem, pneumatic dilation can be performed in any age group and during pregnancy. Pneumatic dilation does not hinder the performance of a future myotomy, and all cost analyses find it less expensive than Heller myotomy over 5 to 10 years. On the other hand, laparoscopic Heller myotomy has the advantage of being a single procedure, the dysphagia relief may be greater at the cost of more troubling heartburn, and a myotomy may be more effective treatment than pneumatic dilation in adolescents and young adults, especially men. Myotomy is definitely the treatment of choice in uncooperative patients and patients in whom pseudoachalasia cannot be excluded. In healthy subjects, we do not offer Botox as an option, because the treatment is not definitive, and the duration of relief short term. On the other hand, Botox injections are the treatment of choice in patients who are poor surgical candidates and the elderly because it is safe, improves symptoms and generally older patients require retreatment no more frequently than once a year. Initial treatment of uncomplicated achalasia probably can be handled by experienced community physicians and surgeons. Failures, particularly after surgery, should be referred to Esophageal Centers of Excellence with expertise in pneumatic dilation, repeat myotomy and esophagec- tomy. Using this multidiscipline approach, we have found that over $90 \%$ of achalasia patients can have long term relief or improvement in their dysphagia and good quality of life. ${ }^{20}$ However, few patients are "cured" with a single procedure and intermittent "touch up" procedures (especially pneumatic dilation and sometimes repeat myotomy) may be required.

\section{Conclusion}

There are still many challenges and questions to be answered regarding achalasia and its treatment. We need to understand the triggers leading to the destruction of the esophageal and LES neurons and possibly how to prevent these insults. If this is due to an autoimmune process, one possible alternative therapeutic approach may be immune modulating drugs. Animal studies should continue to explore the potential of stem cell transplantation to restore esophageal and LES function. Recent studies of mice suggest that transplantation of neuronal stem cells injected in the pylorus survive and even express NO synthase. ${ }^{60}$ Future large, randomized, prospective trials will need to compare laparoscopic Heller myotomy and pneumatic dilation to address the superiority of one technique to the other over a 5 to 10 year period, or to determine which therapies should be reserved for a certain subset of patients. Initial trials should be done in Centers of Excellence with surgeons and gastroenterologists skilled with this disease, but a later comparative study in the community setting would best define where these patients should be initially treated. Finally, some endoscopic enthusiasts will see if a successful myotomy can be performed through the endoscope.

\section{References}

1. Willis T. Pharmaceutic rationalis: sive diatriba de medicamentorum; operatimibus in humano corpore. London: Hagae-Comitis 1674.

2. Mayberry JF. Epidemiology and demographics of achalasia. Gastrointest Endosc Clin N Am 2001;11:235-248.

3. Eckhardt VF, Hoischen T, Bernhard G. Life expectancy, complications, and causes of death in patients with achalasia: results of a 33-year follow-up investigation. Eur J Gastroenterol Hepatol 2008; 20:956-960.

4. Goldblum JR, Whyte RI, Orringer MB, Appelman HD. Achalasia. A morphologic study of 42 resected specimens. Am J Surg Pathol 1994;18:327-337.

5. Goldblum JR, Rice TW, Richter JE. Histopathologic features in esophagomyotomy specimens from patients with achalasia. Gastroenterology 1996;111:648-654.

6. Holloway RH, Dodds WJ, Helm JF, Hogan WJ, Dent J, Arndorfer 
RC. Integrity of cholinergic innervation to the lower esophageal sphincter in achalasia. Gastroenterology 1986;90:924-929.

7. Park W, Vaezi MF. Etiology and pathogenesis of achalasia: the current understanding. Am J Gastroenterol 2005;100:1404-1414.

8. Ruiz-de-León A, Mendoza J, Sevilla-Mantilla C, et al. Myenteric antiplexus antibodies and class II HLA in achalasia. Dig Dis Sci 2002;47:15-19.

9. Moses PL, Ellis LM, Anees MR, et al. Antineuronal antibodies in idiopathic achalasia and gastro-esophageal reflux disease. Gut 2003; 52:629-636.

10. Niwamoto H, Okamoto E, Fujimoto J, Takeuchi M, Furuyama J, Yamamoto Y. Are human herpes viruses or measles virus associated with esophageal achalasia? Dig Dis Sci 1995;40:859-864.

11. Birgissen S, Galinski MS, Goldblum JR, Rice TW, Richter JE. Achalasia is not associated with measles as known herpes or human papilloma viruses. Dig Dis Sci 1997;42:300-306.

12. Facco M, Brun P, Baesso I, et al. T cells in the myenteric plexus of achalasia patients show a skewed TCR repertoire and react to HSV-1 antigens. Am J Gastroenterol 2008;103:1598-1609.

13. Eckardt VF, Stauf B, Bernhard G. Chest pain in achalasia: patient characteristics and clinical course. Gastroenterology 1999;116:13001304.

14. De Oliveira JM, Birgisson S, Doinoff C, et al. Timed barium swallow: a simple technique for evaluating esophageal emptying in patients with achalasia. AJR Am J Roentgenol 1997;169:473-479.

15. Ghosh SK, Pandolfino JE, Rice J, Clarke JO, Kwiatek M, Kahrilas PJ. Impaired deglutitive EGJ relaxation in clinical manometry: a quantitative analysis of 400 patients and 75 controls. Am J Physiol Gastrointest Liver Physiol 2007;293:G878-G885.

16. Pandolfino JE, Kwiatek MA, Nealis T, Bulsiewicz W, Post J, Kahrilas PJ. Achalasia: a new clinically relevant classification by high-resolution manometry. Gastroenterology 2008;135:1526-1533.

17. Gockel I, Eckhard VF, Schmitt T, Junginger T. Pseudoachalasia: a case series and analysis of the literature. Scand J Gastroenterol 2005;40:378-385.

18. Sandler RS, Bozymski EM, Orlando RC. Failure of clinical criteria to distinguish between primary achalasia and achalasia secondary to tumor. Dig Dis Sci 1982;27:209-213.

19. Eckhardt VF, Köhne U, Junginger T, Westermeier T. Risk factors for diagnostic delay in achalasia. Dig Dis Sci 1997;42:580-585.

20. Vela MF, Richter JE. Management of achalasia at a tertiary center - a complicated disease. Gastroenterology 2003;124(suppl 1):A236.

21. Vaezi MF, Baker MF, Achkar E, Richter JE. Timed barium esophagram: better predictor of long term success after pneumatic dilation in achalasia than symptoms assessment. Gut 2002;50:765-770.

22. Eckardt VF, Aignherr C, Bernhard G. Predictors of outcome in patients with achalasia treated by pneumatic dilation. Gastroenterology 1992;103:1732-1738.

23. Hulselmans M, Vanuytsel T, Degreef T, et al. Long-term outcome of pneumatic dilation in the treatment of achalasia. Clin Gastroenterol Hepatol 2010;8:30-35.

24. Kadakia SC, Wong RK. Graded pneumatic dilation using Rigiflex achalasia dilators in patients with primary esophageal achalasia. Am J Gastroenterol 1993;88:34-38.

25. Richter JE. Update on the management of achalasia: balloons, surgery and drugs. Expert Rev Gastroenterol Hepatol 2008;2:435-445.
26. Zerbib F, Thétiot V, Richy F, Benajah DA, Message L, Lamouliatte H. Repeated pneumatic dilations as long-term maintenance therapy for esophageal achalasia. Am J Gastroenterol 2006;101:692-697.

27. O'Connor JB, Singer ME, Imperiale TF, Vaezi MF, Richter JE. The cost-effectiveness of treatment strategies for achalasia. Dig Dis Sci 2002;47:1516-1525.

28. Karanicolas PJ, Smith SE, Inculet RI, et al. The cost of laparoscopic myotomy versus pneumatic dilatation for esophageal achalasia. Surg Endosc 2007;21:1198-1206.

29. Vantrappen G, Hellemans J, Deloof W, Valembois P, Vandenbroucke J. Treatment of achalasia with pneumatic dilation. Gut 1971;12:268-275.

30. Eckardt VF, Kanzler G, Westermeier T. Complications and their impact after pneumatic dilation for achalasia: prospective long-term follow-up study. Gastrointest Endosc 1997;45:349-353.

31. Ghoshal UC, Kumar S, Saraswat VA, Aggarwal R, Misra A, Choudhuri G. Long-term follow-up after pneumatic dilation for achalasia cardia: factors associated with treatment failure and recurrence. Am J Gastroenterol 2004;99:2304-2310.

32. Vela MF, Richter JE, Khandwala F, et al. The long-term efficacy of pneumatic dilation and Heller myotomy for the treatment of achalasia. Clin Gastroenterol Hepatol 2006;4:580-587.

33. Kostic S, Kjellin A, Ruth M, et al. Pneumatic dilation or laparoscopic cardiomyotomy in the management of newly diagnosed idiopathic achalasia. Results of a randomized controlled trial. World J Surg 2007;31:470-478.

34. Metman EH, Lagasse JP, d'Alteroche L, Picon L, Scotto B, Barbieux JP. Risk factors for immediate complications after progressive pneumatic dilation for achalasia. Am J Gastroenterol 1999;94:1179-1185.

35. Guardino JM, Vela MF, Connor JT, Richter JE. Pneumatic dilation for the treatment of achalasia in untreated patients and patients with failed Heller myotomy. J Clin Gastroenterol 2004;38:855-860.

36. Heller E. Extramukoese cardinplastik bein chronischen cardiopsasmus mit dilation des oesophagus. Mitt Grenzgeb Med Chir 1914;27:141-145.

37. Vaezi MF, Richer JE. Current therapies for achalasia: comparison and efficacy. J Clin Gastroenterol 1998;27:21-35.

38. Pelligrini C, Wetter LA, Patti M, et al. Thoracoscopic esophagomyotomy. Initial experience with a new approach for the treatment of achalasia. Ann Surg 1992;216:291-299.

39. Oelschlager BK, Chang L, Pellegrini CA. Improved outcomes after extended gastric myotomy for achalasia. Arch Surg 2003;138: 490-495.

40. Richards WO, Torquati A, Holzman MD, et al. Heller myotomy versus Heller myotomy with Dor fundoplication for achalasia: a prospective randomized double-blind clinical trial. Ann Surg 2004;240: 405-415.

41. Portale G, Constantini M, Rizzetto C, et al. Long-term outcome of laparoscopic Heller-Dor surgery for esophageal achalasia: possible detrimental role of previous endoscopic treatment. J Gastrointest Surg 2005;9:1332-1339.

42. Sharp KW, Khaitan L, Scholz S, Holzman MD, Richards WO. 100 consecutive minimally invasive Heller myotomies: lessons learned. Ann Surg 2002;235:631-639.

43. Gockel I, Junginger T, Eckardt VF. Long-term results of conven- 
tional myotomy in patients with achalasia: a prospective 20-year analysis. J Gastrointest Surg 2006;10:1400-1408.

44. Constantini M, Zanninotto G, Guirroli E, et al. The laparoscopic Heller-Dor operation remains an effective treatment for esophageal achalasia at a minimum 6-year follow-up. Surg Endosc 2005;19: 345-351.

45. Bonatti H, Hinder RA, Klocker J, et al. Long-term results of laparoscopic Heller myotomy with partial fundoplication for the treatment of achalasia. Am J Surg 2005;190:874-878.

46. Csendes A, Braghetto I, Burdiles P, Korn O, Csendes P, Henríquez A. Very late results of esophagomyotomy for patients with achalasia: clinical, endoscopic, histologic, manometric, and acid reflux studies in 67 patients for a mean follow-up of 190 months. Ann Surg 2006;243:196-203

47. Shimi S, Nathanson LK, Cuschieri A. Laparoscopic cardiomyotomy for achalasia. J R Coll Surg Edinb 1991;36:152-154.

48. Kostic S, Kjellin A, Ruth M, et al. Pneumatic dilation or laparoscopic myotomy in the management of newly diagnosed idiopathic achalasia. World J Surg 2007;31:470-478.

49. Boeckxstaens GE, Annese V, des Varannes SB, et al. The European Achalasia Trial: a randomized multi-centre trial comparing endoscopic pneumodilation and laparoscopic myotomy as primary treatment of idiopathic achalasia. Gastroenterology 2010;138(suppl 1): S53.

50. Lopushinsky SR, Urbach DR. Pneumatic dilation and surgical myotomy for achalasia. JAMA 2006;296:2227-2233.

51. Hoogerwerf WA, Pasricha PJ. Pharmacologic therapy in treating achalasia. Gastrointest Endosc Clin North Am 2001;11:311-324.
52. Bortolotti M, Mari C, Lopilato C, Porrazzo G, Miglioli M. Effects of sildenafil on esophageal motility of patients with idiopathic achalasia. Gastroenterology 2000;118:253-257.

53. Annese V, Bassotti G, Coccia G, et al. A multicenter randomized study of intrasphincteric botulinum toxin in patients with oesophageal achalasia. Gut 2000;46:597-600.

54. Pasricha PJ, Rai R, Ravich WJ, Hendrix TR, Kalloo AN. Botulinum toxin for achalasia: long-term outcome and predictor of response. Gastroenterology 1996;110:1410-1415.

55. Vaezi MJ, Richter JE, Wilcox CM, et al. Botulinum toxin versus pneumatic dilation in the treatment of achalasia: a randomized trial. Gut 1999;44:231-239.

56. Fishman VM, Parkman HP, Schiano TD, et al. Symptomatic improvement in achalasia after botulinum toxin injection of the lower esophageal sphincter. Am J Gastroenterol 1996;91:1724-1730.

57. Mikaeli J, Fazel A, Montazeri G, Yaghoobi M, Malekzadeh R. Randomized controlled trial comparing botulinum toxin injection to pneumatic dilatation for the treatment of achalasia. Aliment Pharmacol Ther 2001;15:1389-1396.

58. Panaccione R, Gregor JC, Reynolds RP, Preiksaitis HG. Intrasphincteric botulinum toxin versus pneumatic dilatation for achalasia: a cost minimization analysis. Gastrointest Endosc 1999;50:492-498.

59. Vaezi MF, Richter JE. Diagnosis and management of achalasia. American College of Gastroenterology Practice Parameter Committee. Am J Gastroenterol 1999;94:3406-3412.

60. Micci MA, Learish RD, Li H, Abraham BP, Pasricha PJ. Neural stem cell express RET, produce nitric oxide, and survive transplantation in the GI tract. Gastroenterology 2001;121:757-766. 